\title{
Chris Bateman wins award
}

Izindaba News Editor and Healthcare Gazette Editor Chris Bateman last month won the Commentary and Analysis category in the annual Discovery Health Journalism awards for his story entitled 'Mental health under-budgeting undermining SA's economy' ${ }^{[1]}$ The citation read, in part: 'In presenting analysis together with a well-chosen personal narrative, Bateman made a persuasive and indispensable case for proper care.' Chris has won the category three times previously and 'Best Trade Publication' twice since 2008.

1. Bateman, C. Mental health under-budgeting undermining SA's economy. S Afr Med J 2015;105(1):7-8. DOI:10.7196/SAMJ.9166

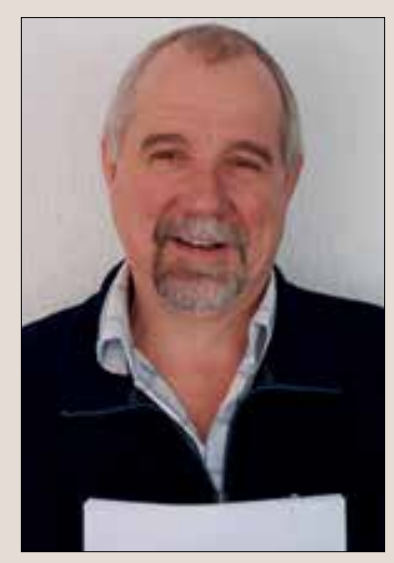

